\title{
"Falar que não existe machismo... Claro que existe!": entrevista com Carola Saavedra
}

Por Christian Grünnagel ${ }^{1}$ e Doris Wieser ${ }^{2}$

\section{Primeira parte, Frankfurt, outubro 2013.}

\section{O que significa ser homem ou ser mulher para você?}

Eu acho que ser homem ou ser mulher é uma coisa que varia de acordo com a sociedade e com o tempo. Então, por exemplo, ser mulher no século XIX significava corresponder a determinadas expectativas. Já hoje as expectativas são outras. Agora, se você me perguntar, "Existe uma essência do que é ser mulher e ser homem?", eu acho que o que existe são lugares que você ocupa. Não que você ocupe esse lugar sempre, pode trocar de lugar. Então, talvez exista uma essência do lugar que você ocupa, mas não da pessoa, do ser mulher ou do ser homem em si. Há sempre uma mudança, um processo em que tudo vai mudando de novo.

Quer dizer que a masculinidade e a feminilidade, segundo você, não são coisas da natureza, mas sim um fenômeno formado pela sociedade?

Se há algum aspecto da natureza, eu acho que não tem como definir. Claro, existem aspectos óbvios: a mulher pode ter filhos, a mulher pode engravidar, questões hormonais, enfim. Mas a forma como isso se apresenta psiquicamente ou socialmente, eu acho que também varia. Se existe, eu acho que é muito difícil de definir. Parece-me que, fora a questão do corpo, trata-se de lugares que você ocupa e esses lugares variam de acordo com a sociedade. O que acho que cria essa discussão é você não ter como definir o que, no corpo de mulher, faz com que ela se relacione como mulher. Se você me disser, por exemplo, "A mulher sente de tal forma, porque ela tem um corpo de mulher", responderia que talvez um homem, que pode ser inclusive um travesti ou um

\footnotetext{
${ }^{1}$ Doutor em letras românicas e professor do Instituto de Filologia Românica da Universidade de Giessen, Giessen, Alemanha. E-mail: christian.gruennagel@ romanistik.uni-giessen.de

2 Doutora em literatura ibero-americana e professora do Instituto de Filologia Românica da Universidade de Göttingen, Göttingen, Alemanha. Atualmente bolsista de pós-doutorado da Fundação Alexander von Humboldt na Universidade de Lisboa. E-mail: doris.wieser@phil.unigoettingen.de
} 
transexual, se coloca nessa mesma posição de mulher, com esse corpo feminino, apesar de não ser geneticamente uma mulher. Eu acho que isso seria a aproximação mais plausível.

Você acha que existe um conceito tipicamente brasileiro da masculinidade? Em comparação com os países que você conhece bem, como a Alemanha e o Chile.

Eu acho que existem papéis menos flexíveis. Então, quando você pensa na cultura latino-americana, está muito mais bem definido o que é ser homem ou ser mulher. Uma coisa é a cultura; outra coisa é a realidade, como as coisas acontecem. Mas a ideia do homem protetor e da mulher dona da casa cuidando dos filhos ainda é uma ideia muito forte, mas não necessariamente uma realidade. Já na cultura alemã, ao contrário, esses papéis não são tão fixos. Quer dizer, os papéis que ditam como se comporta uma mulher ou um homem em casal se entrelaçam na Alemanha com muito mais frequência. Na vida latino-americana, isso também acontece, só que a gente tende a definir esses papéis muito separadamente. A mulher se veste assim, o homem de tal forma. É uma divisão de tarefas em que tanto o homem quanto a mulher trabalham, mas, além disso, a mulher cuida dos filhos, da casa. Não que o homem não cuide, mas a maior parte do trabalho é dela. Então acho que ainda se vê com um certo estranhamento, por exemplo, um homem que resolve adotar um filho, sozinho ou com outro homem. Quando ando em Berlim, eu vejo muitos casais com filhos adotados e ninguém está olhando, ninguém está nem aí. Isso seria impossível no Brasil, quer dizer, um casal de dois homens com os filhos adotados. É uma coisa que todo mundo para para olhar. Então eu acho que esse conceito masculino é menos permeável no Brasil. Acho que o homem se sente atingido no seu ser masculino por esse outro que representa uma outra possibilidade.

Quando pensamos na América Latina, aqui na Europa aparece muitas vezes a palavra "machismo". É um preconceito europeu dizer que a América Latina é machista. Você diria que o machismo é realmente tão importante assim, hoje em dia, no Brasil?

Sim. Não é que ele seja importante. Ele existe, está presente na vida das pessoas. Claro que está muito mais presente do que na Alemanha. Para mim isso não é teoria, é prática. O machismo também tenta definir o que 
é uma mulher. Como ela deve se comportar ou como o homem deve se comportar, como educam as meninas e os meninos, o que se espera de cada um deles. Acho que esses papéis ainda são muito determinados, algo que eu não vejo na Alemanha. Então falar que não existe machismo... Claro que existe!

Uma socióloga australiana, R. W. Connell, afirma que há vários "projetos" de masculinidade. Ela fala de masculinidade no plural: "masculinidades". Você acha que há também vários tipos de masculinidade no Brasil? Como se distingue, por exemplo, a masculinidade de um homem da classe média da masculinidade de um homem da periferia ou da favela?

Eu acho que isso é muito mais forte do que na Europa. Acho que a ideia da masculinidade é muito mais heterogênea no Brasil do que aqui. No Brasil, é claro que, quanto menos educação o homem tiver, no sentido de uma educação formal, mais ele vai tender à violência. Mas, se você olhar as estatísticas da classe média e alta, há violência contra mulheres da mesma forma. Só que essa violência está mais escamoteada porque a mulher da classe média ou alta não vai à delegacia denunciar o marido como a mulher da classe pobre, que não tem alternativa. Se ela não for, vai morrer. Então, quer dizer, acho que no Brasil, ou na América Latina, há uma masculinidade que permeia, e há diferenças que são caladas por questões sociais, mas que são pequenas em comparação com a Europa.

Seus livros têm narradores em primeira pessoa, tanto homens como mulheres, por exemplo, em Toda terça, a Laura e o Javier. Você vê alguma diferença técnica na hora de criar um personagem masculino ou feminino? É mais difícil ou mais fácil criar um personagem do seu sexo?

Na verdade, a técnica é a mesma, no sentido de que você tem que se colocar no lugar do outro. Por exemplo, o Javier. Estou mais preocupada com o olhar dele como personagem, não estou pensando "ele é homem" ou "a Laura é mulher". Estou pensando: "Quem é essa pessoa?". Claro que, por exemplo, o personagem central do Flores azuis é um cara recém-separado que tem uma filha pequena que fica com ele nos finais de semana, mas ele não estava acostumado a tomar conta da filha. Quem tomava conta da filha era a mulher. De repente, eles se veem nos finais de semana. Uma menina de três anos, com a qual ele não sabia o que fazer, nem como lidar com ela, como ser pai. Fora de 
um sistema tradicional de "pai, mãe e filho na mesma casa". Claro que isso é uma questão masculina. É aquele homem que foi acostumado com "eu sou provedor e do resto a mulher cuida". De repente, ele tem que cuidar, tem que pentear a filha, dar banho nela. Ele é obrigado a assumir um papel que antes não existia. É uma questão masculina, mas quando crio um personagem não estou pensando em "como é um homem?". Eu penso em como seria ali naquela situação.

Em Toda terça eu me pergunto por que você criou uma personagem feminina que está no Brasil e um personagem sul-americano que está na Europa. Por que esse contraste entre homem e mulher e ao mesmo tempo entre continentes e culturas? Não seria mais fácil comparar as duas visões se os dois tivessem o mesmo sexo ou se estivessem no mesmo país?

Primeiro, eu não estava pensando em comparar culturas. Também não estava pensando em comparar o que é ser homem e o que é ser mulher. $\mathrm{Na}$ realidade, eu estava querendo contar a história do Javier e da Laura. E a história do Javier só poderia ser contada na Alemanha, porque ele é estrangeiro. A da Laura poderia ser contada em qualquer lugar. Por acaso, ela está no Rio, mas o que importa é que ela está no consultório do analista. As referências não estão tão claras. Eu estava preocupada em contar a história de cada um.

Falando ainda do Javier: quando eu li o livro, pensei "eu conheço esse Javier". Já conheci homens latino-americanos aqui, na Europa, que experimentaram várias carreiras, mas abandonaram todos os estudos pela metade, às vezes trabalham, às vezes não, mas nunca num emprego formal, vivem às custas da namorada e parecem estar totalmente despreocupados com o futuro. Você acha que esse tipo de homem sulamericano realmente é típico aqui na Alemanha ou Europa?

Não diria que é típico. Eu poderia criar outras histórias de sulamericanos na Europa. Do homem que chega aqui casado e depois enfrenta uma crise e se separa. Ou do homem trabalhador. Quer dizer, tem de tudo. Não se pode cair no clichê. Existem vários outros tipos de sul-americanos na Europa. Acho que eu quis escrever sobre um determinado tipo, mas poderia ter inventado outro. Conheço muitos casos de homens que vieram casados para cá e desandaram, a mulher não se adaptou, mas ele, sim, e acabaram se separando. O que eu acho que o Javier tem, sim, é o machismo. Javier é um machista. Talvez seja 
intelectual, mas também é machista, como muitos intelectuais sulamericanos. Acho que passa por essa figura do homem a forma como ele lida com a cultura alemã, como ele lida com uma mulher alemã.

Acho que é uma boa descrição. É chamativo também que, apesar de ele ostentar um ar de superioridade, no fundo é preguiçoso, não consegue fazer nada com a vida dele e depende da Ulrike. Isso realmente é machismo?

Acho que é um tipo de machismo, porque a superioridade dele não é só em relação à Ulrike, mas diz respeito a tudo. A minha visão do personagem é que ele é um homem que se sente muito atacado por tudo e de alguma forma tem que se defender daquilo. Ele se defende com a ironia, não se permitindo se envolver emocionalmente, mantendo uma distância. Se você for pensar o que está ali por trás, é uma sensação de não pertencimento. É como se ele dissesse: "Vocês não me querem, eu também não quero vocês." Essa é a relação.

Acho que ele é cínico.

Sim, essa é a palavra. Ele é sarcástico o tempo todo. Acho que esse sarcasmo vem sempre de um medo, de uma proteção. Porque ele é o cara que se perdeu. Para mim é um personagem que não sabe de onde vem, para onde vai e que está vivendo um dia depois do outro. Incapaz de chegar até o outro. O grande problema dele é nunca conseguir estender uma ponte para o outro. Ele está completamente isolado.

Falando agora das mulheres do romance. Gostei muito do contraste entre a Ulrike e a Laura. Também são pessoas muito realistas para mim, no sentido de que eu tenho a impressão de já ter convivido com elas. Penso que, na Alemanha, há muitas Ulrikes e, no Brasil ou na América Latina, há muitas Lauras. A Ulrike, que é sempre politicamente correta, preocupada pelo meio ambiente, pela igualdade, faz tudo corretinho, certinho. A Laura, moça de classe média, acha que não é preciso trabalhar, porque tem um namorado, que é casado, mas que paga o apartamento dela. Ela começa uma carreira e larga. Ela não pensa muito no futuro porque acha que sempre vai aparecer algum homem para pagar as contas dela. Então eu me pergunto: Seria possível uma Laura na Alemanha e uma Ulrike no Brasil? 
Acho muito difícil. Uma Ulrike no Brasil só se fosse uma alemã no Brasil. Porque é uma mentalidade muito alemã. Não existia isso no Brasil. Agora, aos poucos, as pessoas estão começando a se preocupar se a produção é orgânica ou não... essas coisas ecológicas. Acho que pode existir uma Laura na Alemanha. Já uma Ulrike no Brasil, acho que é mais difícil. E a Ulrike é baseada em uma situação que tem a ver com um conto do Borges. Daí que vêm os nomes. No conto a personagem se chama "Ulrica", e o cara é o "Javier". E ele conhece uma personagem "Ulrica" que eu acho que é escandinava. Enfim os personagens são baseados nessa ideia.

Para mim a Laura é uma personagem antipática. Todas as mentiras que ela conta para o terapeuta, a artificialidade, a preocupação com a beleza. "Será que eu vou precisar de uma lipo?" Isso eu ouvi muito no Brasil. Ela é uma pessoa típica nesse sentido. Você queria fazer uma crítica a esse tipo de comportamento ou a essa classe social? Ou ao papel da mulher nessa classe?

Não pensei em fazer uma crítica, pensei em mostrar. Não estou criticando como autora. Queria mostrar o personagem para que o leitor, ele mesmo, pudesse chegar às suas conclusões. Outra pessoa pode achar adorável. Já ouvi pessoas dizendo "Eu me identifiquei totalmente com a Laura, eu sou a Laura!".

Ela vai "toda terça" à terapia. Mas eu fiquei com a impressão de que, para ela, tudo isso só é um jogo com a finalidade de seduzir o terapeuta. No fim de contas, ela precisa mesmo de terapia?

Acho que é uma das pessoas que precisam muito fazer terapia, mas não conseguem. Ela começa fazendo outras coisas. Ela mente e inventa. A única intenção da Laura é seduzir o terapeuta. Em termos psicológicos, se eu fosse psicóloga, eu diria que ela precisa, sim, ser internada. Está muito maluca. Ela não confronta os seus problemas. Não quer nem saber. Pelo contrário, ela foge o tempo todo, procura subterfúgios.

Eu vejo também paralelos entre os dois personagens latino-americanos, 0 Javier e a Laura. Primeiro, os dois se caracterizam por certa inércia e despreocupação com a vida profissional. Segundo, os dois estão com uma pessoa que não amam de verdade. Pelo outro lado, a Ulrike e as amigas dela fazem tudo "certinho" e os dois latino-americanos não conseguem ser felizes, não conseguem estar com uma pessoa realmente amada. Mas o 
romance não explica como eles chegaram a esse estado de solidão. Há uma explicação para isso?

Quando você começa um romance, tem que começar de um ponto. Não gosto de explicar o passado. Eu gosto de mostrar a pessoa naquele determinado ponto como se tivesse uma lupa. Então você pode imaginar como ela chegou a esse ponto. Para mim é um livro sobre o desamor. São personagens que não amam, que não são capazes de amar. Estão de alguma forma fechados em uma cápsula, por medo, incapacidade, mil motivos. A gente fala tanto no amor, em livros, novelas; mas amar mesmo, nem todo mundo ama. Poucas pessoas são capazes de amar um amor verdadeiro.

O amor e a falta de amor parece ser um tema central nos três romances, não é? Por que esse tema é tão importante para a sua literatura?

É um tema central. Tanto que eu vejo os três livros quase como uma trilogia do amor. São formas diferentes. Acho que cada autor tem suas obsessões. O que me chama muito a atenção é isso: duas pessoas se amam, ou há a incapacidade de as pessoas amarem, de chegarem até o outro. Muitos dizem: "A Carola escreve sobre a impossibilidade da comunicação". Isso também é uma forma do desamor. É uma obsessão minha: eu precisei de três livros para fechar o tema.

Falando do final do romance [Toda terça], ele fecha com uma aproximação lésbica entre a Laura e a Camila. O Javier tem um caso com a Camila em Frankfurt. Depois a Camila volta para o Brasil e encontra a Laura, uma amiga de infância,. A Laura começa a se aproximar da Camila, mas a Camila não quer. A Camila sente, não sei, um nojo, uma aversão. Eu não gostei do final, porque não gosto da representação do amor lésbico como algo negativo. Mas, para a Camila, é muito negativo e eu acho que até para a Laura, porque não é amor, é outra coisa.

Como tudo no livro é outra coisa. Você vê o amor lésbico e o heterossexual e eles são igualmente o desamor. Eu não faço diferença entre os sexos, os tipos de amor. Tanto o lésbico quanto o hétero. No caso da Laura e da Camila o que acontece é que tudo o que a Laura faz é se apossar da história da personalidade da Camila. Então a sedução é quase um momento automático, porque a Laura está se apossando daquilo que a Camila já estava fazendo. A Camila vê a outra como uma 
invasora da vida dela. É como alguém que está ali para tirar algo. É uma coisa assustadora para ela, como um filme de terror. Acho que eu coloco isso entre elas porque é importante que fosse entre duas mulheres. É muito mais fácil duas mulheres se aproximarem e se identificarem completamente. Então essa identificação completa era a ideia do livro. Quando a Laura vai contar essas coisas para o analista, ela vai de certa forma ocupando o lugar que era da Camila.

\section{Quer dizer que a Laura é incapaz de sentir algo profundo.}

Por ninguém. Nem homem, nem mulher. Para mim a Laura vai buscar, tanto com um homem quanto com uma mulher, sentir algo que ela não é capaz de sentir. O sexo não tem a ver só com amor, tem a ver com mil outras coisas.

Como você julga o estado da homossexualidade hoje no Brasil? Porque já existe a lei do casamento...

Agora melhorou muito. A verdade é que o Brasil não é Berlim. No Brasil, duas mulheres que se beijam na rua podem ser agredidas, é escandaloso. Isso chama muita atenção. É muito duro ser lésbica no Brasil. Tenho amigas que sei que sofrem, têm que mentir no trabalho, mentir para a família. Porque é mentira dizer que aceitamos isso na sociedade. Não aceitamos, não. Os homens, a mesma coisa, não aceitam. Não acho que tenha liberdade nenhuma. Acho que a sociedade é muito dura e acho que ainda tem muita coisa a fazer por esses direitos que existem na lei. Eu me lembro: morava em Berlim e via um casal de homens com filhos jogando videogame no restaurante. Ninguém estava olhando. Se fosse no Brasil, teriam chamado a polícia. Isso sempre me chamou muito a atenção, uma liberdade real que existe na Alemanha e não tem nada a ver com a realidade brasileira.

\section{Segunda parte, Göttingen, maio 2013.}

Paisagem com dromedário trata, em sua essência, de arte e amor. O tema não tem, portanto, uma relação direta com o Brasil. Qual é o motivo disso? É essa uma tendência geral da literatura contemporânea brasileira? 
Eu acredito que essa é uma tendência entre muitas outras. Existe essa vertente, mas também há uma série de outras correntes, como a literatura urbana, que tematiza o fenômeno da violência, ou mesmo autores como Luiz Ruffato, que escreve sobre o mundo da classe trabalhadora, e também Ronaldo Correa de Brita, que reinventa o regionalismo.

O fato de meu livro não ter a ver com o Brasil se deve acima de tudo aos temas que abordo. Certa vez uma investigadora literária me disse o seguinte - e eu acho que ela tem razão: eu tinha uma certa experiência que tem a ver com minha origem chilena. Minha família sempre foi uma espécie de ilha bilíngue. Nós tínhamos uma conexão muito familiar e íntima uns com os outros e pouco dessa referência externa. Provavelmente minha personalidade se projeta em meus livros. São livros que têm a ver não com lugares específicos, mas com o que se passa no interior das pessoas.

Além disso, eu passei anos fora. Quando eu estava em Guadalajara (México), por exemplo, me pediram para que contasse sobre minhas experiências no Chile. Mas eu não tenho lembranças nenhumas dos meus primeiros anos no Chile. Eu me perguntava quais seriam minhas primeiras memórias e descobria que era meu voo do Chile para o Brasil. Nessa época eu tinha três anos. Eu lembro exatamente o que eu comi, como as comissárias de bordo estavam vestidas, que eu ganhei alguma coisa para poder pintar... Isso é muito simbólico, porque, em minhas lembranças, minha vida começa com esse voo. Certamente por tal motivo eu me interesso mais pelo ser em si do que por circunstâncias especiais de um lugar, porque eu própria não tive um elo muito forte com um determinado local.

Então não foi uma decisão programática. Você não disse a si mesma que o tema da brasilidade já havia sido suficientemente trabalhado na literatura e que talvez fosse o momento de fazer algo novo...

Não, e eu não acredito nessas coisas. Eu não acredito que alguém possa escrever algo bom pensando de forma tão programática. Só se consegue escrever sobre aquilo que move você. Por isso, não é uma decisão pragmática. Escreve-se aquilo que se pode e não aquilo que se quer, e isso deve vir de dentro. 
Já mesmo no título do seu romance há algo que salta às vistas e nos faz notar que o livro não pode tratar do Brasil, que é o fato de haver um dromedário. Antes da leitura eu me perguntei o que esse dromedário poderia significar. Paisagem com dromedário poderia ser o título de uma pintura. É muito ilustrativo. Além disso, eu associo dromedário com o ambiente da cultura árabe ou com um certo aspecto exótico. Que papel desempenha o dromedário para você no desenrolar do romance?

Há várias possibilidades de interpretação. Primeiramente, existe com frequência na arte contemporânea o título "Paisagem com alguma coisa", e às vezes essa "alguma coisa" nem pode ser vista na pintura ou é muito pequena, quase uma mancha imperceptível com a qual se pode imaginar o objeto. Mas o dromedário tem ainda outros significados. Érika diz em algum momento que um dromedário precisa de pouca água e pouca atenção. Eles conseguem sobreviver por muito tempo no deserto, assim como em uma ilha. Eles são autônomos. É mais ou menos assim que se sente Érika. Ela acredita poder viver por muito tempo sozinha, sem relações humanas.

Os temas-chave do seu romance são arte e amor. Essa abordagem transmite a ideia de que o amor tem algo a ver com a arte, ou seja, que se necessita da arte para poder amar, e vice-versa, que é preciso amar para criar arte.

Eu acredito que tanto para a arte quanto para o amor é preciso paixão. Por isso eu quis que Érika fosse artista. Quando se é artista, tem-se uma relação passional com a arte, é como um casamento. Érika tem duas crises: uma crise com seu marido, Alex, e uma crise com a arte. Ambos estão fortemente ligados com sua identidade, com o amor por Alex e por seu trabalho. Eu queria mostrar esses paralelos. Ela está em busca de sua identidade e se pergunta: o que restou após a separação de Alex? O que restou dela como artista?

No relacionamento entre Érika e Alex, Érika é a artista menos talentosa ou, no mínimo, a menos bem-sucedida. Ou seja, o homem é o mais famoso e em certo sentido superior no relacionamento a dois. Até que ponto esse romance trata também dos papéis dos gêneros na sociedade moderna?

Isso não foi planejado, mas talvez essa constelação mostre algo bastante comum. Eu não queria me deter a isso diretamente, mas apenas contar sobre coisas que acontecem no nosso mundo. Mas com certeza é 
possível ler por essa ótica também. Meu intuito foi narrar um relacionamento em que Érika sempre precisa do outro, de tal forma que ela não sabe o que lhe pertence e o que realmente sabe fazer por si própria. Na nossa sociedade isso acontece com mais frequência a mulheres do que a homens.

Por trás disso não há nenhuma agenda política. A constelação surge mais por observações.

Sim, eu não acredito em literatura com uma agenda política. Na minha opinião, a literatura pode tematizar tais coisas, mas não como intenção fundamental. A intenção é sempre a literatura em si.

O romance também contém um discurso crítico sobre a arte. Ambos os protagonistas são artistas de instalação. Há um debate constante sobre a questão se esse tipo de arte também é consumível por pessoas que não são familiarizadas com discursos teórico-artísticos. Emprega-se uma vez a palavra-chave "Documenta", e eu acho que muitos visitantes da Documenta conhecem a sensação de achar que é preciso ser teórico ou historiador da arte para poder utilizar determinados conceitos de interpretação. Até que ponto você própria é afeita ou adversa a esse tipo de arte?

Quando visito uma Documenta encontro obras que eu amo e acho estupendas e outras que acho totalmente idiotas. É sempre assim na arte, tem coisas que se acha bom e tem coisas que se acha ruim. E naturalmente nem sempre aquilo que eu acho bom é o que interessa também aos outros. Eu me interesso por arte contemporânea, por arte conceitual. Mas aqui existem muitas coisas que são totalmente relativas e eu não compreendo. $\mathrm{O}$ que me interessa acima de tudo é a discussão sobre isso.

A literatura corre o risco de chegar a um ponto no qual a construção de sentido por parte do leitor só é possível quando ele dispõe de discursos teóricos, como hoje em dia é frequentemente o caso nas artes visuais?

Se uma literatura é produzida assim, ela nem sequer será comercializada. A diferença é que a literatura está ligada à instancia do mercado. As editoras decidem o que vai ser publicado. Por esse motivo isso não é um grande problema para a literatura. Mas pensemos em algo radical, como Finnegans Wake, de James Joyce. Não é possível ler simplesmente o livro do início ao fim. Cada capítulo deve ser lido e 
estudado ao longo de semanas. Esse tipo de literatura é muito interessante, mas, primeiramente, existem poucos que conseguem produzir algo desse nível e, segundo, essa é apenas uma experiência possível entre muitas. A literatura precisa também de mais, ela precisa de histórias. Mas é importante que exista algo assim, mesmo que não seja acessível a todo o público.

No último capítulo, seu romance se revela como o manuscrito para uma instalação. Tudo que nós, como leitores, temos em forma escrita à nossa frente é, por fim, o modelo para uma instalação numa sala escura de um museu no qual toca uma fita. Essa é uma forma incomum de desenrolar um romance. Você tem a impressão de que esse tipo de extravagância pode gerar refutação ou distância em determinado público?

De acordo com minha experiência isso não incomoda ao leitor, uma vez que por trás disso há uma história. Pode interessar até mesmo o leitor que não tem qualquer conexão a esses discursos artísticos. O leitor pode ler o livro e ver ali uma história de amor ou separação E, assim, aquele que por isso se interessa e com isso se confronta tem acesso a outros planos. Mas a história funciona independentemente disso.

O triângulo amoroso representado começa em primeiro lugar como um relacionamento a dois. Ao que parece, a relação já existe há alguns anos e, quando começa a envelhecer e cair na rotina, se une a ela uma terceira pessoa, que lhe confere uma nova estabilidade. Visto que se trata de um casal de artistas, é possível que o casal precisasse de um espectador que observa tanto sua arte quanto seu relacionamento?

Sim, acho que pode ser lido dessa maneira. É uma boa interpretação. As figuras funcionam como espelhos umas para as outras, mas também como escudos. Karen está lá porque ela espelha Érika e Alex e lhes proporciona uma certa distância entre um e outro. Por meio dessa distância eles conseguem comunicar novamente um com o outro. Tem uma cena em que estão os três na cama. Karen está na frente de Érika, e Alex está sentado perante as duas acariciando Karen. Érika sente como se o corpo de Karen fosse um escudo entre ela e Alex, mas ao mesmo tempo Karen é aquilo que a une a ele. É esse movimento contraditório que possibilita a comunicação. 
Do ponto de vista da técnica de narração, o romance é experimental. A narrativa de Érika compõe-se de gravações de uma fita cassete. Os ruídos ouvidos nelas são transcritos em palavras e impressos em fonte distinta. Como você chegou a essa ideia tão inusitada?

Eu não conheço outro exemplo na literatura. Caso alguém conheça, que faça o favor de me dizer. A ideia partiu do desejo de criar algo vinculado à intermedialidade. Eu queria trabalhar no espaço entre o audiolivro e a literatura, por isso acabei por criar um audiodiário. Eu queria projetar um texto no limiar entre a palavra falada e a escrita. Tais experimentos me interessam no sentido de que possibilitam encontrar novas formas, novos caminhos para contar as mesmas histórias, novos formatos, novas possibilidades. Eu acho que na fronteira entre diferentes mídias é possível encontrar algo assim. 